\title{
Major Land uses on acid Sulfate soils of Hau Giang province, Vietnam
}

\author{
Vo Quang Minh, Pham Thanh Vũ, Le Van Khoa, Thai Thanh Du, Le Quang \\ Tri, Tran Van Dung
}

Department of Land Resources, College of Environment \& Natural Resources, Cantho University, Vietnam

\begin{abstract}
In recent years, rice crop intensification, which has put a lot of pressure and led to a great change in soil resources and its distribution. In Haugiang province of Vietnam, under different land uses, the previous soil map (2008) has changed and out of date. The research aims to update the soil map of the province under different land uses. The collection of 175 soil profile description data, and 51 soil analysis profiles. Soil classification was followed WRB 2006. The results showed that two major soil groups were found, in which four diagnostic horizons (Mollic, Umbric, Plinthic, and Sulfuric); one diagnostic property (Gleyic); and one diagnostic material (Sulfidic) were identified, and 15 soil types were classified. The Gleysols soil group have 14 soil types (hamoGL, hamoGL(hu), monplGL), (moGL(ptip), moGL(ntip), moGL(dtip), (umGL(ptio), huGL(ptio), umpplGL(ntio), umGL(ntio), huGL(ntio), umGL(dtio), (mowsGL(ntip), umwsGL(ntio)) total area of 9,551.32 ha, accounting for 59.34\%; while Anthrosols soil group have one soil type (RGah) area of 66,252.91 ha, accounting for $40.66 \%$.

Soil map of the province was updated according to WRB 2006, which pineapple, sugarcane crops have a high tolerance of acidity and fruit crops are mainly on Anthrosol soil group, where acid sulfate soils, low in soil pH and base saturation, are dominated. While rice cultivation is dominated on most of Gleysols soil groups, including alluvial and acid sulfate soils. The acid sulfate soils of the study area have low pH, high acidity, high Al content, and low base saturation, in which crops need high tolerance of low pH such as pineapple, sugarcane, fruit crops, but most of the crops should grow on a raised bed for easy to leach soil acidity and toxicity.
\end{abstract} Keywords - Soil classification, WRB Acid sulfate Soils, Land uses.

\section{INTRODUCTION}

Intensive farming in the Mekong Delta has been growing rapidly in recent years. Potential land exploitation is taking place very strongly. The intensive cropping process has greatly altered soil properties, especially accelerated soil degradation processes that depleted the nutrient supply of crops [5]. Formerly established soil map of the region has been changed but have not been updated and no longer respond to the practical situation [6]. Especially in Hau Giang province, in particular, many land-use models have been developed that bring high profit for people [7]. However, land-use changes and intensive cultivation does not pay attention to the conservation of soil resources, along with the changes in natural conditions, since soil properties have been changed [6]. Then, the soil properties and types in the region need to be updated according to the changing of land uses for further land use planning and recommendation.

\section{MATERIAL AND METHODS}

Data collection: Collect all soil data (soil map of Hau Giang province in 2008, and current land use map of Hau
Giang Province in 2015, soil data analysis of Hau Giang province from Land Resources Department, College of Natural Resources and Environment, Can Tho University. Soil Survey: 175 soil profiles were described. Selection of sites for soil augering and soil profile descriptions, soil sampling for analysis based on the guidelines included Handbook for soil survey, classification, mapping and land Evaluation of Thai Bat et al., 2015. [4] and Guidelines for soil profile description, FAO (2006) [3].

Soil sampling: Sampling at 51 sites on the surface (Ap) and surface horizons of the actual depth of the soil horizon, to identify the main diagnostic horizons, properties, and material as described in [1] and [2].

Soil Classification Method: Use FAO's World Reference Based System (WRB) to classify soil based on soil diagnostic horizons, properties and materials and the rules of the system [1], [2].

Soil analysis: Soil samples was analysis for soil chemical a soil physics for major parameters in the lab of Department of Soil science, Cantho University for soil diagnostics, properties and materials identification and classification 
Soil mapping: Map of soil was updated from previous soil map based on the soil types classified, and contoured from previous soil map (2008), combined with land use status and field observation results.

GIS: Mapinfo software was used to create the soil map.

\section{RESULTS}

Based on the results of soil survey (175 sites for soil profile description) in 7 districts (Chau Thanh A, Phung
Hiep, Long My, Vi Thuy, Vi Thanh, Nga Bay and Long My Town) and 51 soil profiles for soil profile description and soil sampling for soil analysis. The soil map of Haugiang was updated.

Soil chemical properties of some profiles and major diagnostic horizons, properties and material for soil classification are shown in below tables:

Table 1: Soil properties at some sampling sites

\begin{tabular}{|c|c|c|c|c|c|c|c|c|c|c|c|}
\hline Code & $\begin{array}{c}\text { Soil } \\
\text { groups }\end{array}$ & $\begin{array}{c}\mathrm{pH}_{\mathbf{H} 2 \mathrm{O}} \\
1: 2,5\end{array}$ & $\begin{array}{c}\mathrm{EC} \\
1: 2,5 \\
\mathrm{mS} / \mathrm{cm}\end{array}$ & $\begin{array}{c}\text { Al } \\
\text { me/100 } \\
\text { g }\end{array}$ & $\begin{array}{c}\text { CEC } \\
\text { meq/10 } \\
\text { 0g }\end{array}$ & $\begin{array}{c}\text { Organic } \\
\text { matter } \\
(\$ \backslash \%)\end{array}$ & $\begin{array}{c}\text { K exch, } \\
\text { meq/100g }\end{array}$ & $\begin{array}{l}\text { Na exch, } \\
\text { meq/100g }\end{array}$ & $\begin{array}{l}\text { Ca exch, } \\
\text { meq/100g }\end{array}$ & $\begin{array}{l}\text { Mg exch, } \\
\text { meq/100g }\end{array}$ & $\begin{array}{c}\% \\
\text { Base }\end{array}$ \\
\hline$H G 99$ & Acidic & 3.79 & 0.558 & 8.35 & 13.90 & 3.98 & 0.324 & 0.086 & 3.63 & 2.64 & 48.06 \\
\hline$H G 110$ & Acidic & 3.55 & 0.338 & 8.88 & 17.34 & 4.26 & 0.517 & 0.060 & 1.06 & 3.42 & 29.16 \\
\hline$H G 112$ & Acidic & 3.76 & 0.374 & 9.31 & 14.70 & 4.57 & 0.185 & 0.062 & 1.74 & 2.19 & 28.41 \\
\hline$H G 135$ & Acidic & 4.12 & 1.040 & 4.86 & 16.24 & 15.34 & 0.837 & 0.922 & 1.80 & 5.42 & 55.29 \\
\hline HG 153 & Acidic & 3.11 & 0.725 & 9.50 & 14.84 & 21.56 & 0.568 & 0.144 & 0.28 & 4.75 & 38.69 \\
\hline HG 91 & Alluvial & 4.88 & 0.199 & 0.466 & 15.86 & 4.90 & 0.206 & 0.257 & 7.67 & 4.83 & 81.73 \\
\hline HG 95 & Alluvial & 4.16 & 0.199 & 4.14 & 17.20 & 3.07 & 0.372 & 0.126 & 5.16 & 5.82 & 66.73 \\
\hline HG 108 & Alluvial & 3.67 & 1.700 & 3.79 & 15.41 & 3.84 & 0.411 & 0.189 & 5.83 & 4.11 & 68.40 \\
\hline
\end{tabular}

Table 2: Diagnostic horizons, properties and materials of major soil group in the study area

\begin{tabular}{|c|c|c|c|c|c|c|c|}
\hline No & Soil groups & Soil code & $\begin{array}{l}\text { Diagnostic } \\
\text { horizons }\end{array}$ & $\begin{array}{l}\text { Diagnostic } \\
\text { properties }\end{array}$ & $\begin{array}{c}\text { Diagnostic } \\
\text { material }\end{array}$ & Area (ha) & $(\%)$ \\
\hline 1 & Alluvial & hamoGL & Mollic & Gleyic & & $49,313.83$ & 30.26 \\
\hline 2 & Alluvial & hamoGL(hu) & Mollic & Gleyic & & $6,777.06$ & 4.16 \\
\hline 3 & Alluvial & monplGL & Mollic, Plinthic & Gleyic & & $1,264.69$ & 0.78 \\
\hline 4 & Acid sulfate & $m o G L(p t i p)$ & Mollic & Gleyic & Sulfidic & 821.66 & 0.50 \\
\hline 5 & Acid sulfate & mowsGL(ntip) & Mollic & Gleyic & Sulfidic & $4,946.98$ & 3.04 \\
\hline 6 & Acid sulfate & $m o G L(n t i p)$ & Mollic & Gleyic & Sulfidic & $4,640.34$ & 2.85 \\
\hline 7 & Acid sulfate & $m o G L(d t i p)$ & Mollic & Gleyic & Sulfidic & $2,241.35$ & 1.38 \\
\hline 8 & Acid sulfate & umGL(ptio) & Umbric, Sulfuric & Gleyic & & 251.76 & 0.15 \\
\hline 9 & Acid sulfate & $h u G L(p t i o)$ & Sulfuric & Gleyic & & $8,556.19$ & 5.25 \\
\hline 10 & Acid sulfate & umwsGL(ntio) & Umbric, Sulfuric & Gleyic & & $2,071.05$ & 1.27 \\
\hline 11 & Acid sulfate & umpplGL(ntio) & $\begin{array}{l}\text { Umbric, } \\
\text { Sulfuric, Plinthic }\end{array}$ & Gleyic & & 152.64 & 0.09 \\
\hline 12 & Acid sulfate & umGL(ntio) & Umbric, Sulfuric & Gleyic & & 9.216 .82 & 5.66 \\
\hline 13 & Acid sulfate & huGL(ntio) & Sulfuric & Gleyic & & $6,368,98$ & 3.91 \\
\hline 14 & Acid sulfate & umGL(dtio) & Umbric, Sulfuric & Gleyic & & 86,63 & 0.05 \\
\hline 15 & Acid sulfate & $A T g l$ & & Gleyic & & $66,252,91$ & 40.66 \\
\hline
\end{tabular}


Table 3: The extent of Soil types by WRB system 2006

\begin{tabular}{|c|c|c|c|c|}
\hline & Symbol & Soil type (WRB 2006) & Area (ha) & $\%$ \\
\hline $\mathbf{I}$ & GL & Gleysols & $96,709.98$ & 59.34 \\
\hline 1 & hamoGL & Hapli - Mollic - Gleysols & $49,313.83$ & 30.26 \\
\hline 2 & hamoGL(hu) & Hapli - Humi - Mollic - Gleysols & $6,777.06$ & 4.16 \\
\hline 3 & monplGL & Molli - EndoPlinthic - Gleysols & $1,264.69$ & 0.78 \\
\hline 4 & moGL(ptip) & Molli - EpiProto Thionic - Gleysols & 821.66 & 0.50 \\
\hline 5 & mowsGL(ntip) & $\begin{array}{l}\text { Molli - HypoSali - EndoProto Thionic - } \\
\text { Gleysols }\end{array}$ & $4,946.98$ & 3.04 \\
\hline 6 & moGL(ntip) & Molli - EndoProto Thionic - Gleysols & $4,640.34$ & 2.85 \\
\hline 7 & moGL(dtip) & Molli - BathiProto Thionic - Gleysols & $2,241.35$ & 1.38 \\
\hline 8 & umGL(ptio) & Umbri - EndoOrthi Thionic - Gleysols & 251.76 & 0.15 \\
\hline 9 & huGL(ptio) & Humi - EpiOrthi Thionic - Gleysols & $8,556.19$ & 5.25 \\
\hline 10 & umwsGL(ntio) & $\begin{array}{l}\text { Umbri - HypoSali - EndoOrthi Thionic - } \\
\text { Gleysols }\end{array}$ & $2,071.05$ & 1.27 \\
\hline 11 & umpplGL(ntio) & $\begin{array}{l}\text { Umbri - EpiPlinthi - EndoOrthi Thionic - } \\
\text { Gleysols }\end{array}$ & 152.64 & 0.09 \\
\hline 12 & umGL(ntio) & Umbri - EndoOrthi Thionic - Gleysols & $9,216.82$ & 5.66 \\
\hline 13 & huGL(ntio) & Humi - EndoOrthi Thionic - Gleysols & $6,368.98$ & 3.91 \\
\hline 14 & umGL(dtio) & Umbri - BathiOrthi Thionic - Gleysols & 86.63 & 0.05 \\
\hline II & AT & Anthrosols & $66,252.91$ & 40.66 \\
\hline 1 & ATgl & Gleyic - Anthrosols & $66,252.91$ & 40.66 \\
\hline
\end{tabular}

According to table 1 and 2, most of the soils in Haugiang province have low $\mathrm{pH}$, due to acid sulfate with thionic horizon, the occurrence of Jarosite mottles, with high Fe and Al. Soils in Haugiang have low ECe, meaning that soils are low salinity. Based saturation at some profile is less than $50 \%$ because of low in base cation.

\subsection{Diagnosis horizon, diagnostic properties and diagnostic materials}

\subsubsection{Diagnosis horizons}

Based on the results of the survey, the description and soil analysis of the area showed that there are 4 major diagnostic horizons, according to WRB (2006) definition:

- Mollic horizon: The thickness of the soil horizon at survey sites ranged from 20 to $60 \mathrm{~cm}$, dark colour (Chroma $\leq 3$ ), with the base saturation of $55.29-81.73 \%$ and the organic matter $(3.48-8.31 \%)$. (Fig l)

- Umbric horizon: The thickness of the soil horizon at survey sites ranged from 20 to $60 \mathrm{~cm}$, dark colour (Chroma $\leq 3)$, base saturation ranged from 28.41 to $48.06 \%$ organic matter $(3.53-8.24 \%)$. (Fig 2)

- Plinthic horizon: The survey results show that the Plinthic horizon in Hau Giang province has a depth of 35$80 \mathrm{~cm}$ and ends at 70-150 cm depth (Fig 3)

- Thionic horizon: the results of the soil survey showing that the actual acid sulfate soil (the Munsell colour of mottle is from $2.5 \mathrm{Y} 8 / 6-8 / 8$ occurred at a depth of $40-150$ $\mathrm{cm}$ and end at $100-200 \mathrm{~cm}$. Besides, sulfidic soil material is also identified. (Fig 4)

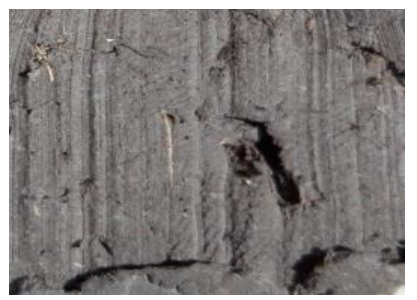

Fig 1: Mollic horizon

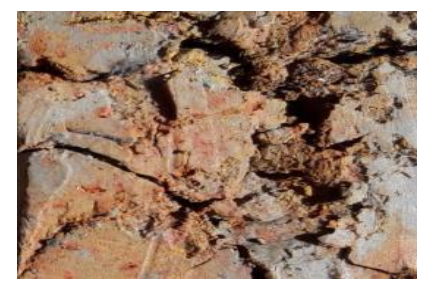

Fig 3: Plinthic horizon

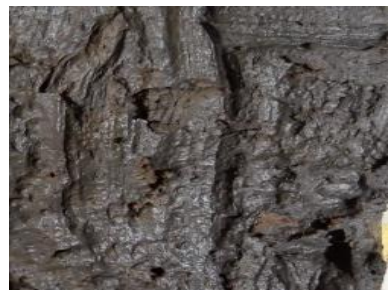

Fig 2: Umbric horizon

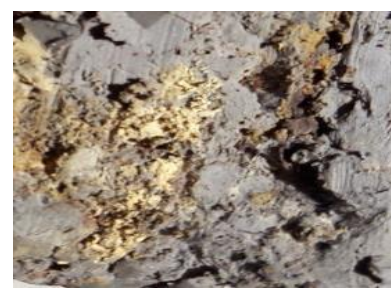

Fig 4: Thionic horizon

\subsubsection{Diagnostic properties}

According to the classification system WRB 2006, there is one Gleyic diagnostic property identified and used for classifying major soil groups in Hau Giang province. The Gleyic property often occurs at a depth of 40-150 cm. (Fig .5) 


\subsubsection{Diagnostic materials}

According to field testing and soil analysis, only sulfidic material identified and often occurs at a depth from 30 to $150 \mathrm{~cm}$. (Fig 6)

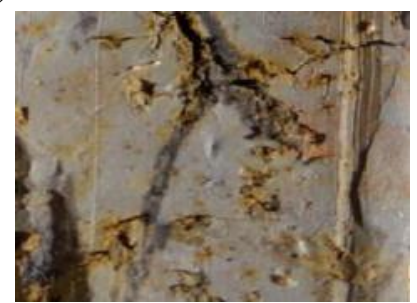

Fig 5: Gleyic property

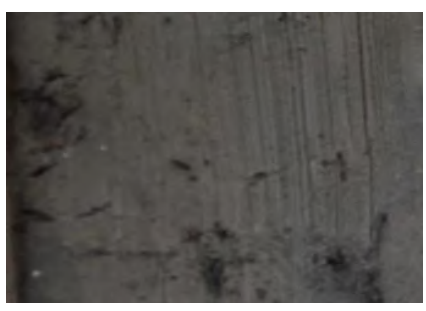

Fig 6: Sulfidic material

\subsection{Major soil groups and soil types in the province}

As the above-identified diagnostic horizon, properties, and material, Hau Giang Province has two major soil groups including Gleysols and Anthrosols, which are shown in Table 3 and Figure 7. There are only two major soil groups as Gleysols and Anthrosol, in which Gleysols soil group occupied the largest area $(96,709.98$ ha, or $50.34 \%)$, while Anthrosols soil group is occupied 66,252.91ha (40.00\%(

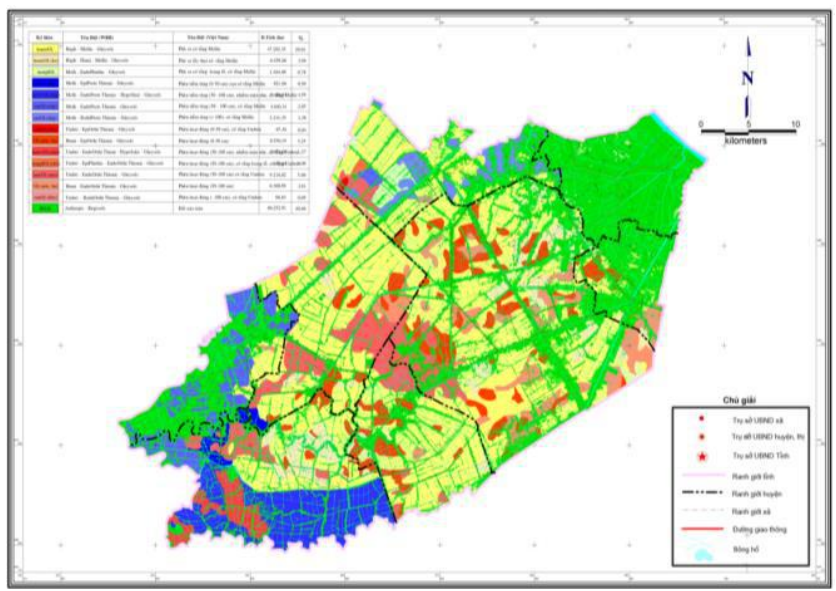

Fig 7: Soil map of Hau Giang province, by WRB system

The Gleysols group in Hau Giang province consists of 14 soil types with a total area of 96,709.98 hectares, accounting for $59.34 \%$ of the province's area. In particular, Hapli-Mollic-Gleysols occupied the largest area, 49,313.8ha (30.26\%); while Umbri-Bathi-Orthi ThionicGleysols occupied the smallest area (86.63ha or $0.05 \%)$.
The Anthrosols soil group occupied 66,252.91 hectares, accounting for $40.66 \%$ of the province and has only one soil type (Gleyic-Anthrosols).

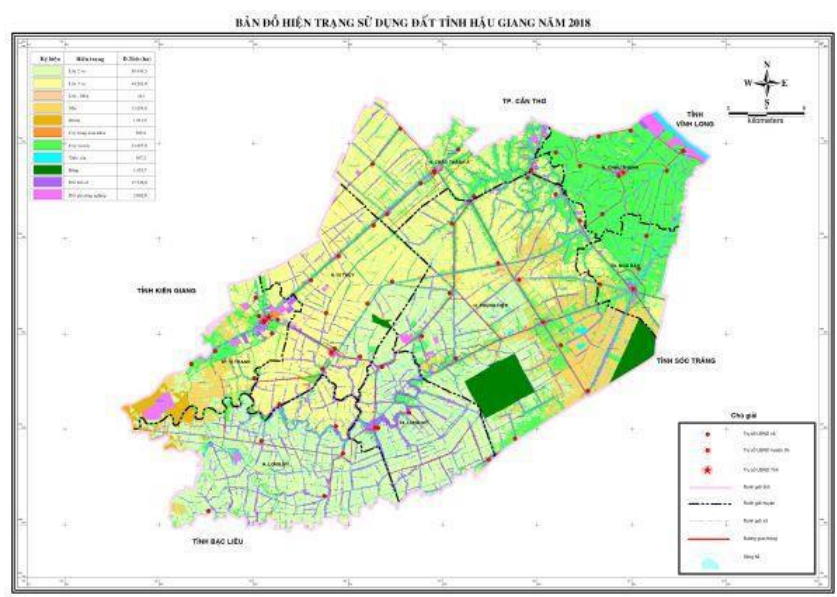

Fig 8: Major land uses map of the study areas

\subsection{Major land uses on soils of the study areas}

According to Table 4, Fig 7 and 8, most of the soils in the province are alluvial soils, then crops can grow well on these soils, but at some soil types with the occurrence of sulfidic material can release toxicity if oxidized, causing high in toxicity and acidity, low $\mathrm{pH}$, high $\mathrm{Al}^{3+}$ and $\mathrm{Fe}^{2+}$, then damage to root crops. These soils have Orthi-Thionic properties, low $\mathrm{pH}$, high toxicity, the result of oxidation of sulfidic material. On these soil types, rice can grow well if under the reduced condition and received freshwater, which can leach toxicity to the canals, and soils get high $\mathrm{pH}$. Otherwise, If freshwater supplied, upland crops can grow well on these soils.

On Anthrosol soil group, Orchard and Upland crops occupied the largest area, $(35,240 \mathrm{ha})$, there is no rice on these soil groups, due to most of the soil is acidic, the occurrent of sulfidic material, low $\mathrm{pH}$, high toxicity. While Pineapple and Sugarcane can tolerate low $\mathrm{pH}$ and high toxicity, and soils need to make a raised bed for leaching of toxicity. (Fig 9). The rest of the areas are urban, nonAgricultural land, or aquacultural. (Fig 11)

On Gleysol soil groups, soils have Gleyic property, it means most of the soils under reduced conditions, higher soil $\mathrm{pH}$ and high toxicity, at sometimes of the year, soil can be oxidized to form the soil mottle. Especially, sulfidic soil material is oxidized to release toxicity then the soil has low $\mathrm{pH}$, but in the wet season, because of high rainfall, soil toxicity leached out and rice can grow well on these soils (83,750 ha). However, upland crops such as sugarcane, corn, can growth on these soils if small raised bed created to kept soi dried and toxicity can be drained during the wet season (Fig 9, 10). 


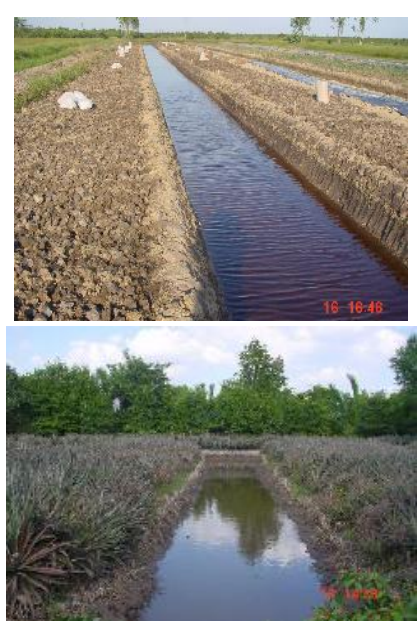

Fig 9: Sugarcane on acid sulfate soil raised bed

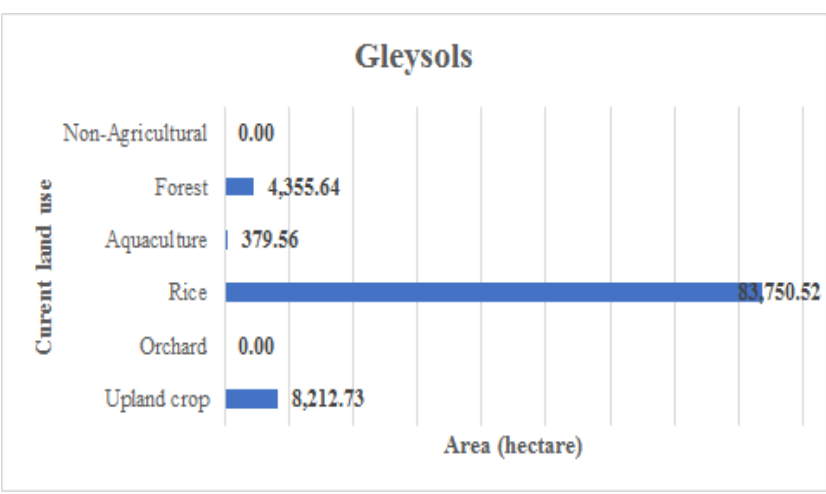

Fig 10: Major land uses on Gleysols soil group

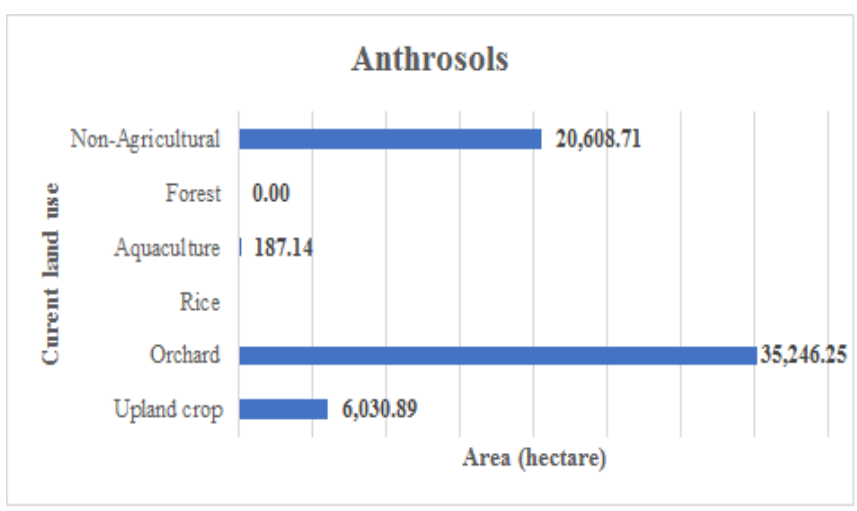

Fig 11: Major land uses on Anthrosols soil group

\section{CONCLUSION}

The soil map of the province was updated based on the previous soil map. Two major soil groups identified from WRB system (Gleysols and Anthrosols). Four diagnostic horizons (Mollic, Umbric, Plinthic and Sulfuric), one diagnostic material (Sulfidic) and one diagnostic property (Gleyic) were identified. Within two major soil groups, 15 soil types have been identified: the Gleysols group of 14 soil types (hamoGL, hamoGL (hu), monplGL), moGL (ptip), moGL (ntip), moGL (dtip), umGL huGL, umGL (ntio), huGL (ntio), umGL (dtio), mowsGL (ntip),
umwsGL (ntio)) with a total area of 96,709.98 hectares accounting for 59, 34\% and Anthrosols with one soil type (ATgl), occupied $66,252.91$ ha, accounting for $40.66 \%$ or $66 \%$.

Rice cultivation is dominated on Gleysols while Orchard and Upland crops with the raised bed are mainly on Anthrosols soils where acid sulfate soils are dominated.

The acid sulfate soils of the study area have low $\mathrm{pH}$, high acidity, Al toxicity and low base saturation, in which crops need high tolerance of low $\mathrm{pH}$ such as pineapple, sugarcane, fruit crops, but most of the crops should grow on a raised bed for easy to leach soil acidity and toxicity.

\section{ACKNOWLEDGEMENTS}

This study is funded in part by the Can Tho University Improvement Project VN14-P6, (supported by a Japanese ODA loan), and Ministry of Education support for the annual study, and VLIR (CTU-Belgium) projects, and Department of Science and technology of Hau Giang province.

\section{REFERENCES}

[1] FAO, World Reference Center for Soil Resources. 84 World Soil Resource Report, Food and Agriculture Organization of the United Nation Rome, Italy. 1998.

[2] FAO, World Reference Base for Soil Resources 2006. World Soil Resource report. Food and agriculture organization of the United Nation Rome, Italy. 2006a.

[3] FAO. Guidelines for soil profile description (Fourth Edition). ISBN 92-5-105521-1. Rome, Italia. 2006b.

[4] Le Thai Bat, Vu Nang Dung, Bui Thi Ngoc Dung, Do Dinh Dai, Phan Quang Khanh, Do Dinh Sam, Luyen Huu Cu, Phan Van Tu. Handbook for Soil survey, classification, mapping and evaluation. Vietnamese Soil Science Association. Agricultural Publishing house, Hanoi, Vietnam. 2015.

[5] Vo Quang Minh, Nguyen Thanh Vu, Nguyen Thị Ngọc Lan, Phạm Thanh Vu, Thai Thanh Du, Le Quang Tri. Soil fertility evaluation for crop growth in Hau Giang province. Proceeding of Mekong delta soil Science conference. 19 Oct 2018. Cantho University, Vietnam. ISBN: 978-604-9541069. Cantho University. In Vietnamese. 2018.

[6] Vo Quang Minh, Le Quang Tri, Pham Thanh Vu, Tran Van Dung, Tran Thanh Thang, Thai Thanh Du, The Basis for Conversion of WRB Soil Classification System (1998) to WRB (2006) for Mekong delta soil classification. Vietnamese Soil Science Journal. No 53, 2018. ISSN 25252216. In Vietnamese. 2018.

[7] Thai Thanh Du, Ong Van Ninh, Pham Thanh Vu, Tran Van Dung, Vo Quang Minh, Le Quang Tri. Soil classification properties following on WRB 2008 classification system in Hau Giang province. Journal of Soil Science. No 52. 2017. ISSN: 2225 2516. Vietnamese Soil Science Association. 2017. (In Vietnamese) 